\title{
Long term effects on the olfactory system of exposure to hydrogen sulphide
}

\author{
Alan R Hirsch, Gilberto Zavala
}

\begin{abstract}
Objective-To study chronic effects of hydrogen sulphide $\left(\mathrm{H}_{2} \mathrm{~S}\right)$ on cranial nerve I (nervi olfactorii), which have been only minimally described.

Methods-Chemosensations (smell and taste) were evaluated in eight men who complained of continuing dysfunction 2-3 years after the start of occupational exposure to $\mathrm{H}_{2} \mathrm{~S}$. Various bilateral (both nostrils) and unilateral (one nostril at a time) odour threshold tests with standard odorants as well as the Chicago smell test, a three odour detection and identification test and the University of Pennsylvania smell identification test, a series of 40 scratch and sniff odour identification tests were administered.

Results-Six of the eight patients showed deficits of various degrees. Two had normal scores on objective tests, but thought that they continued to have problems. $\mathrm{H}_{2} \mathrm{~S}$ apparently can cause continuing, sometimes unrecognised olfactory deficits.

Conclusion-Further exploration into the extent of such problems among workers exposed to $\mathrm{H}_{2} \mathrm{~S}$ is warranted.

(Occup Environ Med 1999;56:284-287)
\end{abstract}

Keywords: hydrogen sulphide; smell; taste disorders

Hydrogen sulphide $\left(\mathrm{H}_{2} \mathrm{~S}\right)$, a colorless gas easily recognised at $0.025 \mathrm{ppm}$ by its distinctive rotten egg odour, is well known to affect diffuse areas of the human nervous system including the cortex, subcortex, cranial nerves, and peripheral nervous system. ${ }^{12}$ Its effects on cranial nerves II, V, and VIII have been extensively documented, but its chronic effects on cranial nerve I (nervi olfactorii) have been minimally described. ${ }^{34}$

An acute effect of $\mathrm{H}_{2} \mathrm{~S}$ on the olfactory nerve is temporary paralysis, or olfactory fatigue, which disables the sense of smell, rendering it a poor warning system for detecting the continued presence of the gas. ${ }^{35}$ Acute effects have generally been described as transient.

Chronic effects of $\mathrm{H}_{2} \mathrm{~S}$ on the olfactory system have been described in only one instance ${ }^{5}$ : a 46 year old man working next to a sludge centrifuge at a sewage treatment plant was overcome and rendered unconscious for less than a minute. After regaining consciousness, a neurological examination showed reduced memory, impaired concentration, and complete loss of the sense of smell. His electroencephalogram (EEG) was normal at that time. Ten months after the accident, the patient continued to complain of tiredness, impaired initiative, expressive aphasia, and episodes of trembling. His loss of the sense of smell persisted, except that he was able to detect ammonia. Examination at that time showed impaired visual accommodation and fusion, but neuropsychological test results were normal. Two years after the exposure, CT, and EEG were normal, as were neuropsychological test results, and his sense of smell had returned to normal. Whether his sense of smell was objectively assessed or his subjective evaluation reported, however, is not documented.

Our purpose in the present study was to evaluate chronic effects on olfaction after exposure to $\mathrm{H}_{2} \mathrm{~S}$.

\section{Methods}

SUBJECTS

Eight men who came for medical evaluation of continuing problems with smell and taste had had accidental exposure to $\mathrm{H}_{2} \mathrm{~S}$ during their jobs 2-3 years previously.

\section{Patients 1-4}

On 8 January 1993, 900 pounds of $\mathrm{H}_{2} \mathrm{~S}$ were released into the environment over a 2.5 hour period at a construction site at a gas refinery in St Croix, Virgin Islands. Two years later we examined four of the workers, who had experienced various local irritating effects including lacrimation, eye irritation, nausea, vomiting, headache, sore throat, and skin irritation. They had also experienced chemosensory phenomena consistent with $\mathrm{H}_{2} \mathrm{~S}$ exposure, the smell of rotten eggs, and a strong metallic taste. ${ }^{6}$ None of the patients had lost consciousness during the accident. At the time of the accident, atmospheric $\mathrm{H}_{2} \mathrm{~S}$ concentrations were not obtained, but in previous months the patients had been exposed to similar low level releases, when the recorded concentrations of $\mathrm{H}_{2} \mathrm{~S}$ were as high as $243 \mathrm{ppm}$ in the work area. The past exposures of these four patients is considered chronic. 
Table 1 Clinical data 3 years after exposure to $\mathrm{H}_{2} \mathrm{~S}$

\begin{tabular}{|c|c|c|c|c|c|c|c|c|}
\hline \multirow[b]{2}{*}{ Patient No } & \multicolumn{4}{|c|}{ At refinery construction site (chronic) } & \multicolumn{4}{|c|}{ At petroleum plant gas leak (acute) } \\
\hline & 1 & 2 & 3 & 4 & 5 & 6 & 7 & 8 \\
\hline Age (y) & 45 & 39 & 44 & 41 & 52 & 69 & 40 & 61 \\
\hline Loss of consciousness with exposure & No & No & No & No & Yes & Yes & Yes & Yes \\
\hline Rate of exposure & Chronic & Chronic & Chronic & Chronic & Acute & Acute & Acute & Acute \\
\hline Onset of taste problem & 3 Months after & $\begin{array}{l}\text { 5-10 Months } \\
\text { after }\end{array}$ & Immediate & 2 Years after & Unknown & $\begin{array}{l}1-1.5 \text { Years } \\
\text { after }\end{array}$ & Unknown & Immediate \\
\hline Onset of smell problem & 1 Month after & $\begin{array}{l}5-10 \text { Months } \\
\text { after }\end{array}$ & Immediate & Unknown & $\begin{array}{l}\text { Immediate } \\
\text { increase }\end{array}$ & $\begin{array}{l}1-1.5 \text { Years } \\
\text { after }\end{array}$ & Immediate & Immediate \\
\hline Rate of deficit & $\begin{array}{l}\text { Increased then } \\
\text { no change }\end{array}$ & $\begin{array}{l}\text { Increased then } \\
\text { no change }\end{array}$ & $\begin{array}{l}\text { Increased then } \\
\text { no change }\end{array}$ & $\begin{array}{l}\text { Increased then } \\
\text { no change }\end{array}$ & No change & No change & No change & No change \\
\hline Duration of deficit & To present & To present & To present & To present & To present & To present & To present & To present \\
\hline Phantosmia? & No & Yes & No & No & No & No & No & No \\
\hline Encephalopathy? & Subclinical & Clinical & Clinical & Clinical & Clinical & Clinical & Clinical & Clinical \\
\hline \multicolumn{9}{|l|}{ Smell tests: } \\
\hline \multicolumn{9}{|l|}{ Amoore's bilateral ( $25 \mathrm{ds}$ ): } \\
\hline IV acid & Abnormal & Abnormal & Normal & Normal & & Abnormal & Normal & Normal \\
\hline Diacetyl & Abnormal & Abnormal & Normal & Abnormal & & Normal & Normal & Normal \\
\hline l-Carvone & Normal & Normal & Normal & Normal & & Normal & Normal & Normal \\
\hline PE-alcohol & Normal & Abnormal & Normal & Normal & & Normal & Normal & Normal \\
\hline Thiophane & Normal & Normal & Normal & Normal & & Abnormal & Normal & Abnormal \\
\hline Chicago smell test (CST) & 4 of 6 & 4 of 6 & 4 of 6 & 4 of 6 & 6 of 6 & 3 of 6 & 3 of 6 & 4 of 6 \\
\hline \multirow[t]{2}{*}{ UPSIT smell ID } & 30 of 40 & 35 of 40 & 35 of 40 & 38 of 40 & & 29 of 40 & 17 of 40 & 23 of 40 \\
\hline & Mild hyposmia & Normosmia & Normosmia & Normosmia & & $\begin{array}{l}\text { Moderate } \\
\text { hyposmia }\end{array}$ & Anosmia & $\begin{array}{l}\text { Severe } \\
\text { hyposmia }\end{array}$ \\
\hline \multicolumn{9}{|l|}{ Amoore's unilateral thresholds: } \\
\hline PM carbinol & Normal & Normal & Normal & Normal & & Abnormal & & Abnormal \\
\hline PE phenol & Normal & Normal & Normal & Normal & & Normal & & Normal \\
\hline Naphthalene & Normal & Normal & Normal & Normal & & Normal & & Normal \\
\hline Pyridine & Normal & Normal & Normal & Normal & & Normal & & Normal \\
\hline Cineole & Normal & Normal & Normal & Normal & & Abnormal & & Normal \\
\hline ISOB-ISOB & Normal & Normal & Normal & Normal & & Normal & & Normal \\
\hline IA acetate & Normal & Abnormal & Normal & Normal & & Normal & & Normal \\
\hline PD lactone & Normal & Abnormal & Normal & Normal & & Abnormal & & Normal \\
\hline CA phenone & Normal & Normal & Normal & Normal & & Normal & & Normal \\
\hline \multirow[t]{2}{*}{ Thiophane (ds) } & 15/15 Normal & 15/25 Normal & 15/15 Normal & 20/15 Normal & & $40 / 20$ & & $35 / 25$ \\
\hline & & & & & & Hyposmia & & Hyposmia \\
\hline
\end{tabular}

Patients 5-8

On 14 May 1993, four workers were sent as part of a crew to fix a gas leak at a petroleum plant in Texas. On their arrival at the site of the leak, the workers noted fumes coming out from underground. They also noted that in the surrounding area, the odour of rotten eggs was strong, the grass was brown, and birds lay dead. The workers descended into a trenching system 8 feet deep, 7 feet wide, and 12 feet long. None wore protective garb. While attempting to fix the broken pipe, all were overcome by the gas and were unconscious for several minutes before being discovered. They were treated for gas intoxication, were admitted to the intensive care unit, and spent at least a week in hospital. At the time of exposure, atmospheric $\mathrm{H}_{2} \mathrm{~S}$ concentrations were not obtained, but 3 days after the accident, the concentration of $\mathrm{H}_{2} \mathrm{~S}$ in the gas leaking out of the pipe into the trench was $2873 \mathrm{ppm}$ as measured by the United States Department of Labor and the Occupational Safety and Health Administration (OSHA). When we examined the four patients, 2.5 years had elapsed since their acute exposure. There were no known past or subsequent exposures to $\mathrm{H}_{2} \mathrm{~S}$ in these subjects.

\section{Clinical evaluation}

All patients were asked their subjective experience of anosmia, hyposmia (decreased odour sensitivity), hyperosmia (increased odour sensitivity), phantosmia (phantom smells), dysosmia (deranged sense of smell), hypogeusia (decreased taste sensitivity), phantogeusia (the taste equivalent of phantosmia), and dysgeusia (the taste equivalent of dysosmia). All were asked to follow the instructions in the appendix in preparation for objective tests. They then underwent bilateral (with both nostrils simultaneously) odour detection tests according to the methods of Amoore and Ollman ${ }^{7}$ with the following standard odorants at concentrations of 25 decismels (ds), a normally detectable level (the ds scale of odour levels is modelled after the decibel scale of sound levels): phenyl ethyl methylethyl carbinol (pm carbinol), isovaleric acid (iv-acid), 2,3 butanedione (diacetyl), pentadecalactone (pd-lactone), 1-carvone, phenylethyl alcohol (pe-alcohol), and tetrahydrothiophene (thiophane). They also underwent the Chicago smell test, consisting of three forced choice questions pertaining to odour and three open ended questions pertaining to odour identification. ${ }^{89}$ Most also underwent other olfactory tests: the University of Pennsylvania smell identification test (UPSIT), a series of 40 scratch and sniff forced choice odour identification questions scored according to age and sex as described in the published guidelines for the UPSIT ${ }^{10}{ }^{11}$; and the unilateral (one nostril at a time) threshold tests of Amoore and Ollman for pm carbinol, para ethyl phenol (pe-phenol), naphthalene, pyridine, 1,8 cineole (cineole), isobutyl isobutyrate (isob-isob), isoamyl acetate (ia-acetate), pdlactone, $\alpha$-chloroacetophenone (ca-phenone), and thiophane. (Unilateral threshold tests are scored as normal when either the right or left nostril is normal, as described by Amoore and Ollman. $)^{7}$

\section{Results}

At the time of our evaluations, all patients had subjective complaints of chemosensory dysfunctions, which consisted of hyposmia (eight 
patients), dysosmia (one patient), hyperosmia (one patient), phantosmia (one patient), hypogeusia (eight patients), and phantogeusia (one patient). Problems began immediately for three of the four patients who had acute exposure at the site of the gas leak, but for only one of the four patients exposed at the construction site. The onset of their problems ranged from immediately to 2 years after exposure (table 1).

Objective test results are summarised in table 1. Patients Nos 3 and 5 had normal scores on objective tests, but still considered subjectively that their chemical senses were deficient.

All three from the acutely exposed group who took the UPSIT odour identification test had poor scores, whereas three of the four in the chronic group had normal scores and the fourth was only mildly hyposmic.

\section{Discussion}

An impaired ability to identify odours along with a normal ability to detect them as shown by our patient No 7 has been described to occur with head trauma and may indicate the existence of a lesion of the central nervous system rather than a peripheral lesion in the olfactory nerves. ${ }^{12}$ All of our patients with acute exposure were deficient in their ability to identify odour. Such olfactory deficit could be due to the loss of consciousness and head trauma associated with falling.

Patient No 1, however, was mildly hyposmic on the UPSIT without having lost consciousness and without head trauma. This deficit in the case of our subjects, could be due to the neurotoxic effect of the $\mathrm{H}_{2} \mathrm{~S}$ on the olfactory receptor site or through the retrograde degeneration of the olfactory nerves as they project through the olfactory bulb and tract to the olfactory cortex.

As some of our construction worker patients had histories of considerable toxic exposures including use of alcohol which we have shown can induce olfactory deficit, ${ }^{13}$ it seems possible that our findings of olfactory deficits are unrelated to exposure to $\mathrm{H}_{2} \mathrm{~S}$, and instead are associated with confounding factors-such as collateral toxic exposures.

\section{Conclusions}

As long as three years after their exposure to $\mathrm{H}_{2} \mathrm{~S}$, a high percentage if not all of our patients continue to have olfactory deficits. The long duration of this deficit indicates that it may be permanent.

Patients Nos 3 and 5 who complained of deficits yet were normosmic on tests may have originally been more sensitive than the average, and thus experience real losses.

Patients who have been exposed to $\mathrm{H}_{2} \mathrm{~S}$ should be routinely screened for olfactory deficits and if any are found, vigilant monitoring for $\mathrm{H}_{2} \mathrm{~S}$ must be undertaken at the work site. Also, these patients must be advised to take precautions at home, including the use of smoke detectors, gas detectors, and food tasters.
Poorly documented effects on the chemical senses have also been seen after exposures to various other neurotoxins including nitrogen tetroxide $^{14}$ and benzene. ${ }^{15}$

In our industrial society, chemosensory dysfunction may well be a hidden epidemic among workers exposed to various toxic chemicals. The extent of such problems among workers exposed to $\mathrm{H}_{2} \mathrm{~S}$ and other industrial effluviums is a subject deserving of further careful exploration.

\section{Appendix: Questionnaire}

As we are testing abnormalities of smell and taste, the following precautions must be taken:

- You may eat or drink no caffeine for at least 48 hours before your visit (see list below of foods and beverages containing caffeine) ${ }^{\star}$

- You may drink no alcohol for at least 4 days before your visit

- You may eat no pastry items for 24 hours before your visit

- From the midnight before your visit, you may have none of the following; food, gum, cigarettes, or any drink other than water

IT IS IMPORTANT THAT YOU FOLLOW THESE INSTRUCTIONS TO INSURE THE VALIDITY OF THESE TESTS

- From the midnight before your test day, you should use no scented soap, cosmetics, deodorants, shaving cream, aftershave, perfumes, or lipsticks. The only underarm deodorant you may use is Gillette roll on

- From the midnight before your visit, you may use only shampoo with no or minimal smell - that is, ivory shampoo

- You may brush your teeth, but we ask you not to use toothpaste

- All your usual medications should be taken and if you have diabetes you should eat.

${ }^{\star}$ Foods and beverages containing caffeine that you should try to avoid:

Chocolate

Coffee

Cola

Tea

Cocoa

$\mathrm{NoDoz}$

Other over the counter products that are "stimulants"

be sure to read your labels

1 Berger AR, Schaumburg H. Disorders of the peripheral Berger AR, Schaumburg H. Disorders of the peripheral
nervous system. In: Rosenstock L, Cullen MR, eds. Textnervous system. In: Rosenstock $\mathrm{L}$, Cullen MR, eds. Text-
book of clinical occupational and environmental medicine. Pook of clinical occupational and envir

2 Polinsky RJ, Martin JB. Disorders of the autonomic nervous system. In: Isselbecher KJ, Braunwald E, Wilson JD, et al, eds. Principles of internal medicine. New York: McGraw-Hill, 1994;2344-7.

3 Reiffenstein RJ, Hulbert WC, Roth SH. Toxicology of hydrogen sulfide. Annu Rev Pharmacol Toxicol 1992;10934.

4 Glass DC. A review of the health effects of hydrogen sulfide exposure. Ann Occup Hyg 1990;34:323-7.

5 Tevdt B, Skyberg K, Aaserud O, et al. Brain damage caused by hydrogen sulfide; a follow-up study of six patients. Am $\mathcal{f}$ Ind Med 1991;20:91-101.

6 Hirsch AR. Chronic neurotoxicity of acute hydrogen sulfide exposure without loss of consciousness. In: American occupational health conference, 26 April to 3 May 1996. San Antonio: American College of Occupational and EnvironAntonio: American College

7 Amoore J, Ollman B. Practical test kits for quantitatively evaluating the sense of smell. Rhinology 1983;21:49-54. 
8 Hirsch AR, Cain DR. Evaluation of the Chicago smell test in a normal population [abstract]. Chem Senses 1992;17: in a norm.

9 Hirsch AR, Gotway MB, Harris AT. Validation of the Chicago smell test in patients with subjective olfactory loss [abstract]. Chem Senses 1993;18:571.

10 Doty RL, Shaman P, Dann M. Development of the University of Pennsylvania smell identification test: standardized microencapsulated test of olfactory function (monograph). Physiol Behav 1984;32:489-502.

11 Doty RL. Smell identification test administration manual, 3rd edition. Hadden Heights, NJ: Sensonics, 1995.
12 Hirsch AR, Wyse JP. Posttraumatic dysosmia: central $v$ peripheral. F Neurol Orthop Med Surg 1993;14:152-5.

3 Hirsch AR, Bussell GS. Effects of inebriation on olfaction. $\mathcal{F}$ Invest Med 1995;43:422A.

4 Hirsch AR. Neurotoxicity as a result of acute nitrogen tetroxide exposure. International Congress on Hazardous Waste: Impact on Human and Ecological Health. Atlanta: US: Department of Health and Human Services, Public Health Agency for Toxic Substances and Disease Registry, 1995:177

15 Doty RL. Handbook of olfaction and gustation. New York: Marcel Dekker, 1995:345-65. 